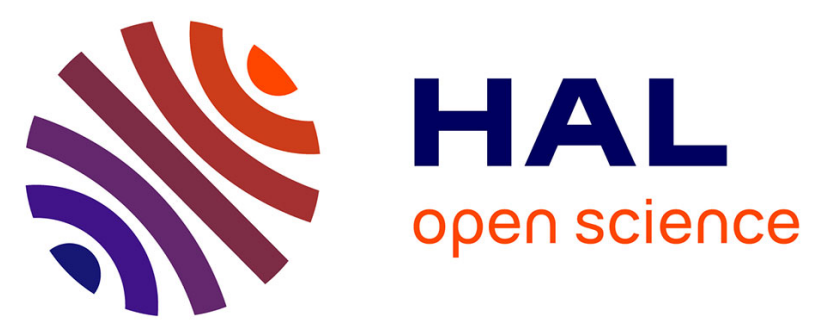

\title{
A structural investigation of SmCo5/Fe nanostructured alloys obtained by high-energy ball milling and subsequent annealing
}

J M Le Breton, R Lardé, H. Chiron, V. Pop, Dominique Givord, Olivier Isnard, I. Chicinas

\section{To cite this version:}

J M Le Breton, R Lardé, H. Chiron, V. Pop, Dominique Givord, et al.. A structural investigation of $\mathrm{SmCo5} / \mathrm{Fe}$ nanostructured alloys obtained by high-energy ball milling and subsequent annealing. Journal of Physics D: Applied Physics, 2010, 43 (8), pp.5001. 10.1088/0022-3727/43/8/085001 . hal-00569765

\section{HAL Id: hal-00569765 https://hal.science/hal-00569765}

Submitted on 25 Feb 2011

HAL is a multi-disciplinary open access archive for the deposit and dissemination of scientific research documents, whether they are published or not. The documents may come from teaching and research institutions in France or abroad, or from public or private research centers.
L'archive ouverte pluridisciplinaire HAL, est destinée au dépôt et à la diffusion de documents scientifiques de niveau recherche, publiés ou non, émanant des établissements d'enseignement et de recherche français ou étrangers, des laboratoires publics ou privés. 


\title{
A structural investigation of $\mathrm{SmCo}_{5} / \mathrm{Fe}$ nanostructured alloys obtained by high energy ball milling and subsequent annealing
}

\author{
J.M. Le Breton ${ }^{1}$, R. Lardé ${ }^{1}$, H. Chiron ${ }^{1}$, V. Pop ${ }^{2}$, D. Givord ${ }^{3}$, O. Isnard ${ }^{3}$, I. \\ Chicinas ${ }^{4}$ \\ ${ }^{1}$ Groupe de Physique des Matériaux, UMR CNRS 6634, Université de Rouen \\ 76801 Saint Etienne du Rouvray, France \\ ${ }^{2}$ Faculty of Physics, Babes-Bolyai University, \\ 400084 Cluj-Napoca, Romania \\ ${ }^{3}$ Institut Néel, CNRS et Université Joseph Fourier, BP 166 \\ 38042 Grenoble cedex 9, France \\ ${ }^{5}$ Materials Science and Technology Dept., Technical University of Cluj-Napoca, 103- \\ 105 Bd. Muncii. 400641 Cluj-Napoca, Romania \\ E-mail : jean-marie.lebreton@univ-rouen.fr
}

\begin{abstract}
SmCo}_{5} / \mathrm{Fe}$ nanostructured alloys with $20 \mathrm{wt} \% \mathrm{Fe}$, obtained by high energy ball milling of $\mathrm{SmCo}_{5}$ and $\mathrm{Fe}$ powders, were investigated by ${ }^{57} \mathrm{Fe}$ Mössbauer spectrometry, X-ray diffraction and tomographic atom probe. The Mössbauer analysis reveals that during the first stages of milling, an interdiffusion of Co and Fe occurs, leading both to the formation of $\alpha$ $\mathrm{Fe}(\mathrm{Co})$ regions in $\alpha-\mathrm{Fe}$ and to the introduction of $\mathrm{Fe}$ in $\mathrm{SmCo}_{5}$ regions. Annealing at temperatures up to $650^{\circ} \mathrm{C}$ for $0.5 \mathrm{~h}$ promotes interdiffusion further leading to the formation of an unique $\alpha-\mathrm{Fe}(\mathrm{Co})$ phase and a $\mathrm{Fe}$-richer $\mathrm{Sm}(\mathrm{Co}, \mathrm{Fe})_{5}$ phase. The $\mathrm{Co} / \mathrm{Fe}$ interdiffusion is confirmed by tomographic atom probe analysis. The data are discussed and compared to the results of previous magnetic measurements.
\end{abstract}

\section{Introduction}

Nanocrystalline exchange-spring "hard-soft" magnets are composite magnetic materials consisting of two magnetic phases, one soft and one hard, mixed in a nanostructure in order to combine the high coercivity of the hard magnetic phase with the high magnetisation of the soft magnetic phase. These composite materials exhibit magnetic properties which are interesting both from a fundamental point of view and for applications [1-5]. The exchange-spring behaviour can be understood on the basis of the intrinsic parameters of the hard and soft magnetic phases which are coupled by exchange $[6,7]$. However, the role of the microstructure in the spring mechanism is not well understood [7-10]. In previous investigations, we established the determinant influence of the microstructure on the hardsoft exchange coupling in $\mathrm{SmCo}_{5} / \alpha-\mathrm{Fe}$ powders obtained by mechanical alloying [11-14].

Mechanical alloying is a widely used preparation technique to obtain nanocrystalline structures exhibiting original magnetic properties including exchange spring [1, 15-24]. It involves the synthesis of materials by high-energy ball milling, in which pure or pre-alloyed elements are milled to achieve alloys or composite materials formation. We concentrate here on the mechanical milling technique to blend two different magnetic phases. We applied mechanical milling to synthesize $\mathrm{SmCo}_{5} / \alpha-\mathrm{Fe}$ nanocomposites starting from a mixture of $\mathrm{SmCo}_{5}$ powder (milled for two hours) and $20 \mathrm{wt} \%$ of elemental iron. The coercivity and the remanence were found to be dependent upon the process conditions and they could be improved by adjusting the milling and/or heat treatment conditions (time and temperature) [11-14]. Microstructural investigations of as-milled and annealed powders showed that the initial magnetic phases are destroyed upon milling, and that annealing the as-milled samples permit recovering the initial phases $[11,13,14]$. However, our previous Mössbauer investigations 
suggested that $\mathrm{Fe} / \mathrm{Co}$ interdiffusion occur during the process [11]. Since then, this result has been confirmed by other authors [25-27].

In the present study, we proceed to a systematic study of the microstructure of $\mathrm{SmCo}_{5} / \alpha-\mathrm{Fe}$ alloys by Mössbauer spectrometry with the aim to follow accurately the evolution of the Fe-containing phases upon milling and subsequent annealing. The results are conforted by tomographic atom probe analysis and interpreted in relation with the magnetic properties of the materials, by considering the influence of the $\mathrm{Fe} / \mathrm{Co}$ interdiffusion on the exchange coupling phenomenon.

\section{Experimental}

An alloy ingot with the $\mathrm{SmCo}_{5}$ nominal composition was prepared by induction melting under argon atmosphere. The purity of the elements was $99.9 \%$. The ingot was crushed into small pieces and it was subsequently mechanically milled for two hours in a high energy planetary mill under argon atmosphere. The $\mathrm{SmCo}_{5}$ powder thus obtained was mixed with an iron powder (grain size below 40 $\mu \mathrm{m})$ in a ratio of $80\left(\mathrm{SmCo}_{5}\right) / 20(\mathrm{Fe})$ weight percent, corresponding to a ratio of $75\left(\mathrm{SmCo}_{5}\right) / 25(\mathrm{Fe})$ atomic percent. The mixture was mechanically milled under argon atmosphere using the high-energy planetary mill. Because the rare earths are very sensitive to oxygen, for the preparation of rare-earth permanent magnetic materials it is necessary to mill in inert atmosphere in order to avoid rare earth oxidation. Several milling times were used ranging from 2 to 8 hours.

In order to investigate the influence of the annealing on the evolution of the $\mathrm{SmCo}_{5} / \alpha-\mathrm{Fe}$ exchange coupling, samples made of the as-milled powder were sealed inside evacuated silica tubes for further heat treatments. These treatments were performed at temperatures ranging from 450 to $650{ }^{\circ} \mathrm{C}$ for 0.5 to 10 hours. The maximum annealing temperature of $650{ }^{\circ} \mathrm{C}$ had been chosen in order to avoid the crystallite growth.

${ }^{57} \mathrm{Fe}$ Mössbauer spectrometry experiments were performed at room temperature in transmission geometry, using a ${ }^{57} \mathrm{Co}$ source in a rhodium matrix. The Mössbauer spectra were fitted according to a least squares method [28]. The isomer shift (relative to metallic $\alpha$-Fe at room temperature) and hyperfine field are denoted $\delta$ and $\mathrm{B}$ respectively. Estimated errors for the hyperfine parameters originate from the statistical errors $\sigma$ given by the fitting program, taking $3 \sigma$.

X-ray diffraction (XRD) patterns were recorded in the angular range $2 \theta=25-100^{\circ}$. For these experiments a Brucker D8 powder diffractometer with the $\operatorname{Co}\left(K \alpha_{1}\right)$ radiation $(\lambda=0,1788970 \mathrm{~nm})$, was used.

The powder milled for $8 \mathrm{~h}$ was analysed by Laser Assisted Wide Angle Tomographic Atom Probe (LAWATAP). The LAWATAP is a 3D analytical high resolution microscope which provides the spatial distribution of atoms of the analysed specimen. The principle of atom probe is based on the field evaporation of surface atoms as ions and their identification by time of-flight mass spectrometry. The high electric field required (a few tens $\mathrm{V} / \mathrm{nm}$ ) is obtained by applying a high voltage to the specimen prepared in the form of a sharply pointed needle (tip radius less than $50 \mathrm{~nm}$ ). The specimen preparation involves a two-step procedure [29]. In the first step, a single powder particle between $\sim 1$ and $\sim 50 \mu \mathrm{m}$ is mounted onto a stainless steel support tip using an ex-situ micro-manipulator and an optical microscope. In the second step, the particle is annularly milled into a very sharp tip by Focused Ion Beam. The tip is biased at a high positive DC voltage $\mathrm{V}_{\mathrm{o}}$ in the range $2-10 \mathrm{kV}$ and cooled to low temperatures $(20-80 \mathrm{~K})$. The vacuum in the analysis chamber is usually in the range $10^{-8} \mathrm{~Pa}$. Surface atoms are then field-evaporated by means of high-frequency $(100 \mathrm{kHz})$ laser pulses superimposed on the DC voltage $\mathrm{V}_{\mathrm{o}}$ [30]. The evaporated atoms are collected by a time-resolved position detector placed in front of the specimen. This allows measuring the time of flight of each ion and recording its impact position. Both informations allow the chemical nature of the evaporated ions to be determined and the position from which the atoms originate at the tip surface to be derived. The atom lateral positions at the surface of the tip sample are obtained from a reverse projection of ion impacts coordinates on the position sensitive detector. The depth position is deduced from the order of 
detection of atoms [31]. The sample is field-evaporated atomic layer by atomic layer, and a typical volume of analysis of $10^{4} \mathrm{~nm}^{3}$ is collected in a few hours. After 3D reconstruction of the analysed volume, the spatial distribution of atoms is observable at the atomic scale in the real space. From the data set of the $3 \mathrm{D}$ reconstruction, the chemical composition or the concentration depth profiles can be calculated everywhere in the analysed volume. More details about tomographic atom probe can be found in references 32 and 33 .

\section{Results}

\subsection{Structural analysis of annealed powders}

The XRD patterns of the powder milled for $8 \mathrm{~h}$ and subsequently annealed are shown in figure 1 . The pattern of the as-milled powder shows only a broad and low intense peak corresponding to $\alpha$-Fe. As the annealing temperature increases, the width of the $\alpha$-Fe peak decreases, and the intensity of the peaks corresponding to the Sm-Co phase increases. This is in agreement with the recrystallization process of the hard and soft phases induced by the annealing treatment and reported before $[11,13,14]$. Additionally, the main peaks of the $\mathrm{Sm}_{2} \mathrm{O}_{3}$ oxide are observed, indicating that some oxidation occured during the annealing treatment.

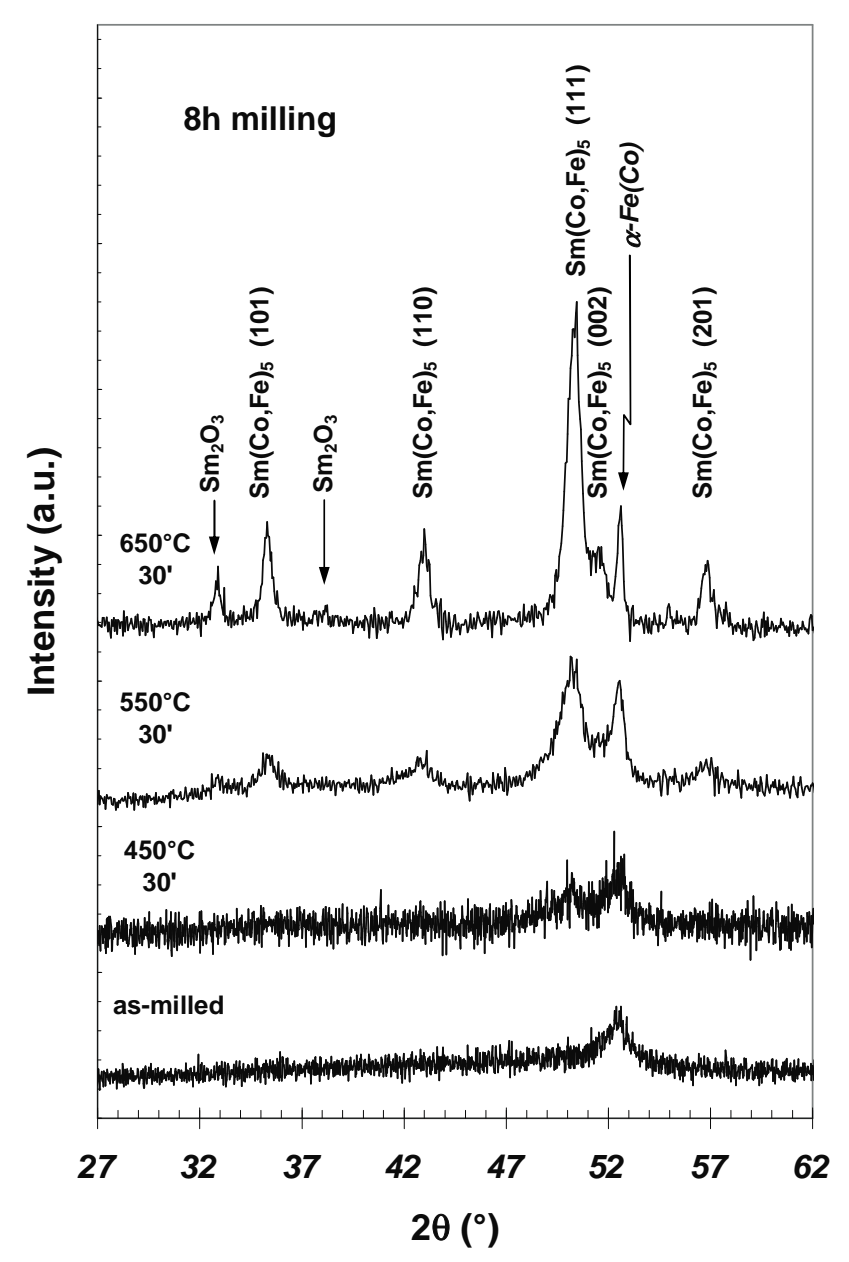

Figure 1. XRD patterns of the powder as-milled for $8 \mathrm{~h}$ and annealed at the indicated temperatures and times. The peaks of the $\mathrm{Sm}(\mathrm{Co}, \mathrm{Fe})_{5}$ phase are indexed in the hexagonal $\mathrm{P} 6 / \mathrm{mmm}$ system.

$$
\left(\lambda_{\mathrm{Co}(\mathrm{K} \alpha 1)}=0,1788970 \mathrm{~nm}\right)
$$


In the pattern of the powder annealed $30^{\prime}$ at $650^{\circ} \mathrm{C}$, the position of the most intense $\alpha$-Fe peak corresponds to a lattice parameter $\mathrm{a}=0.2857 \pm 0.0005 \mathrm{~nm}$. This value is lower than that of the pure $\alpha$ Fe phase $(0.2866 \mathrm{~nm})$. Considering that the Co atomic radius is lower than the $\mathrm{Fe}$ atomic radius, this reveals the presence of Co in the $\alpha$-Fe phase.

The Sm-Co peaks can be indexed in the hexagonal P6/mmm system with lattice parameters a $=0.4900$ $\pm 0.0005 \mathrm{~nm}$ and $\mathrm{c}=0.4100 \pm 0.0005 \mathrm{~nm}$. These lattice parameters are respectively lower and higher, than those of the pure $\mathrm{SmCo}_{5}$ phase $(0.4995 \mathrm{~nm}, 0.3978 \mathrm{~nm})$. Such variations in the lattice parameters are typical of the introduction of transition metal dumbbells in the structure [34,35]. This classically occurs when $\mathrm{Fe}$ atoms are introduced in the $\mathrm{SmCo}_{5}$ phase, in agreement with the fact that the pure $\mathrm{SmFe}_{5}$ phase does not exist [36]. Note that in the following we refer to the formation of the $\mathrm{Sm}(\mathrm{Co}-$ $\mathrm{Fe})_{5}$ alloy whereas, as Fe enters into the phase, the stochiometry is expected to become enriched in transition metal as a result of dumbbell formation.

The grain size has been estimated for both soft and hard magnetic phases, according to Scherrer's formula. A size less than $30 \mathrm{~nm}$ is obtained for the samples milled for $6 \mathrm{~h}$ or more. For the samples milled for $8 \mathrm{~h}$, the $\alpha$-Fe grain size is derived to be of about $18 \mathrm{~nm}$.

\subsection{Mössbauer analysis: Fitting procedure}

All the Mössbauer spectra were recorded at room temperature. They were fitted consistently throughout the whole series of samples, with the following contributions:

- a magnetic contribution with a hyperfine field equal or close to that of $\alpha-\mathrm{Fe}(33.0 \mathrm{~T})$,

- a second magnetic contribution with a hyperfine field of about $27.5 \mathrm{~T}$,

- a paramagnetic contribution, to account for the excess of absorption at the centre of the spectra, when detected.

The magnetic contribution of the $\alpha$-Fe phase has been systematically considered. To take into account its large width in different spectra, this contribution has been fitted with several components, that is a distribution of magnetic sextets.

The second magnetic contribution is characterized by an hyperfine field of about $27.5 \pm 0.3 \mathrm{~T}$, which is typical of a rare-earth / iron compound. This value is in agreement with the room temperature mean hyperfine field of dilute ${ }^{57} \mathrm{Fe}$ nuclei in $\mathrm{SmCo}_{5}$ compound [37]. Consequently, this magnetic component has been attributed to $\mathrm{Fe}$ atoms present in Sm-Co-rich regions. This is in agreement with the XRD analysis, thus confirming that the $\mathrm{Sm}-\mathrm{Co}$ regions destroyed upon milling recrystallize as $\mathrm{Sm}(\mathrm{Co}, \mathrm{Fe})_{5}$ In the following, the second magnetic contribution will be denoted as a $\mathrm{Sm}(\mathrm{Co}, \mathrm{Fe})_{5}$. Preliminary fittings were performed on the spectra where the relative intensity of this contribution is the most important of the series (figure 2). They showed that the $\operatorname{Sm}(\mathrm{Co}, \mathrm{Fe})_{5}$ contribution can be fitted with three components, with hyperfine fields in the range 26.2-29.5 $\mathrm{T}$ (these three components are displayed in figure 2, with the resultant contribution). This has been used for all the spectra.

In some spectra, a paramagnetic contribution has been fitted with a weak relative intensity, which is attributed to Fe-containing paramagnetic phases such as oxides or nanoparticles which are superparamagnetic at room temperature.

\subsection{As-milled powders}

The Mössbauer spectra of the as-milled powders are shown in figure 3. The Mössbauer spectrum of the sample before milling consists uniquely in a magnetic sextet typical for $\alpha-F e$. In the spectra of the as-milled powders, an asymmetric broadening of the lines is observed, as revealed by the shoulders on the external lines of the sextet (see figure 3 ).

In the analysis, this broadening is taken in account by considering magnetic sextets with hyperfine fields between 34 and $36 \mathrm{~T}$, higher than the hyperfine field of pure $\alpha-\mathrm{Fe}(33.0 \mathrm{~T})$. The fact that both the mean hyperfine field $\left\langle\mathrm{B}_{\mathrm{Fe}}\right\rangle$ and the mean isomer shift $\left\langle\delta_{\mathrm{Fe}}\right\rangle$ of this magnetic contribution are larger than $\alpha$-Fe associated values (see figures $4 \mathrm{a}$ and $4 \mathrm{~b}$ ) is characteristic of the presence of Co atoms in the $\alpha$-Fe regions, with a proportion that increases with the milling time [38]. It is worth to note that similar observations were reported for $\mathrm{Fe}_{50} \mathrm{Co}_{50}$ mechanically milled powders [39].

As the milling time is increased, another magnetic component develops (displayed in figure 3 ), with a mean hyperfine field of $27.5 \pm 0.3 \mathrm{~T}$, characterising $\mathrm{Fe}$ atoms having entered in the $\mathrm{SmCo}_{5}$ phase. The relative intensity of this contribution increases with milling time (figure 4c). The relative intensity of 
this contribution being proportional to the $\mathrm{Fe}$ content in the $\mathrm{Sm}(\mathrm{Co}, \mathrm{Fe})_{5}$ regions, its increase is in agreement with an increase in the proportion of $\mathrm{Fe}$ atoms in the $\mathrm{Sm}$-Co-rich regions.

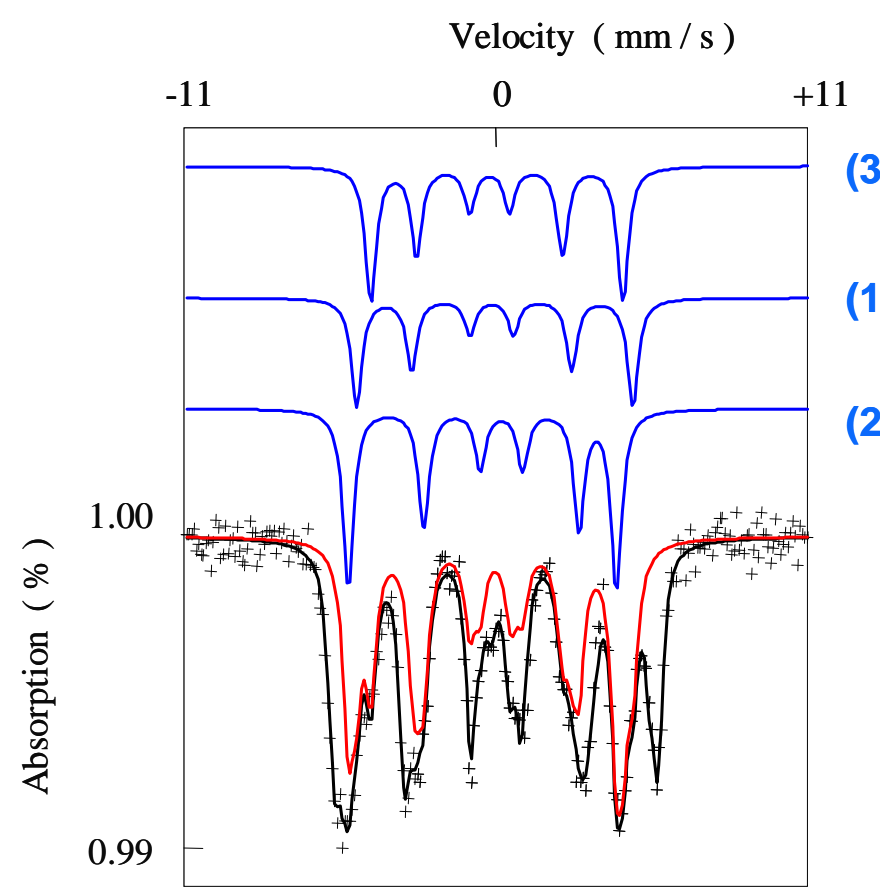

Figure 2. Room temperature Mössbauer spectrum of the $\mathrm{SmCo}_{5} / \mathrm{Fe}$ powder milled for $8 \mathrm{~h}$ and annealed for 30 minutes at $650^{\circ} \mathrm{C}$.

The components of the $\mathrm{Sm}(\mathrm{Co}, \mathrm{Fe})_{5}$ contribution are displayed in blue, their hyperfine fields being 29.4, 28.5 and 26.8 $\mathrm{T}$ for components (1), (2) and (3) respectively.

The resultant $\mathrm{Sm}(\mathrm{Co}, \mathrm{Fe})_{5}$ contribution is displayed in red. 


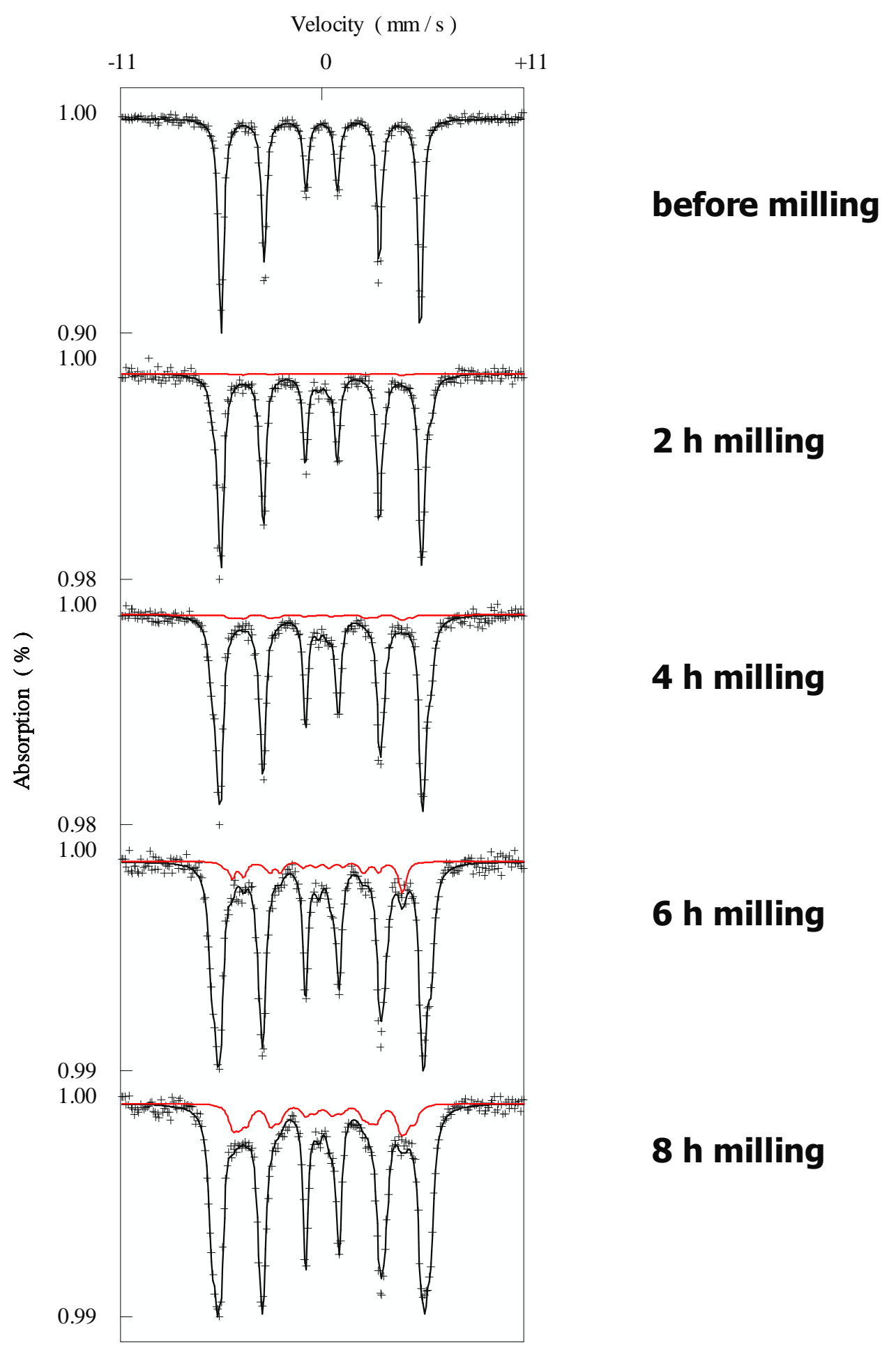

Figure 3. Room temperature Mössbauer spectra of the $\mathrm{SmCo}_{5} / \mathrm{Fe}$ powder before milling and after milling for the indicated times.

The contribution of the $\mathrm{Sm}(\mathrm{Co}, \mathrm{Fe})_{5}$ phase is displayed. 

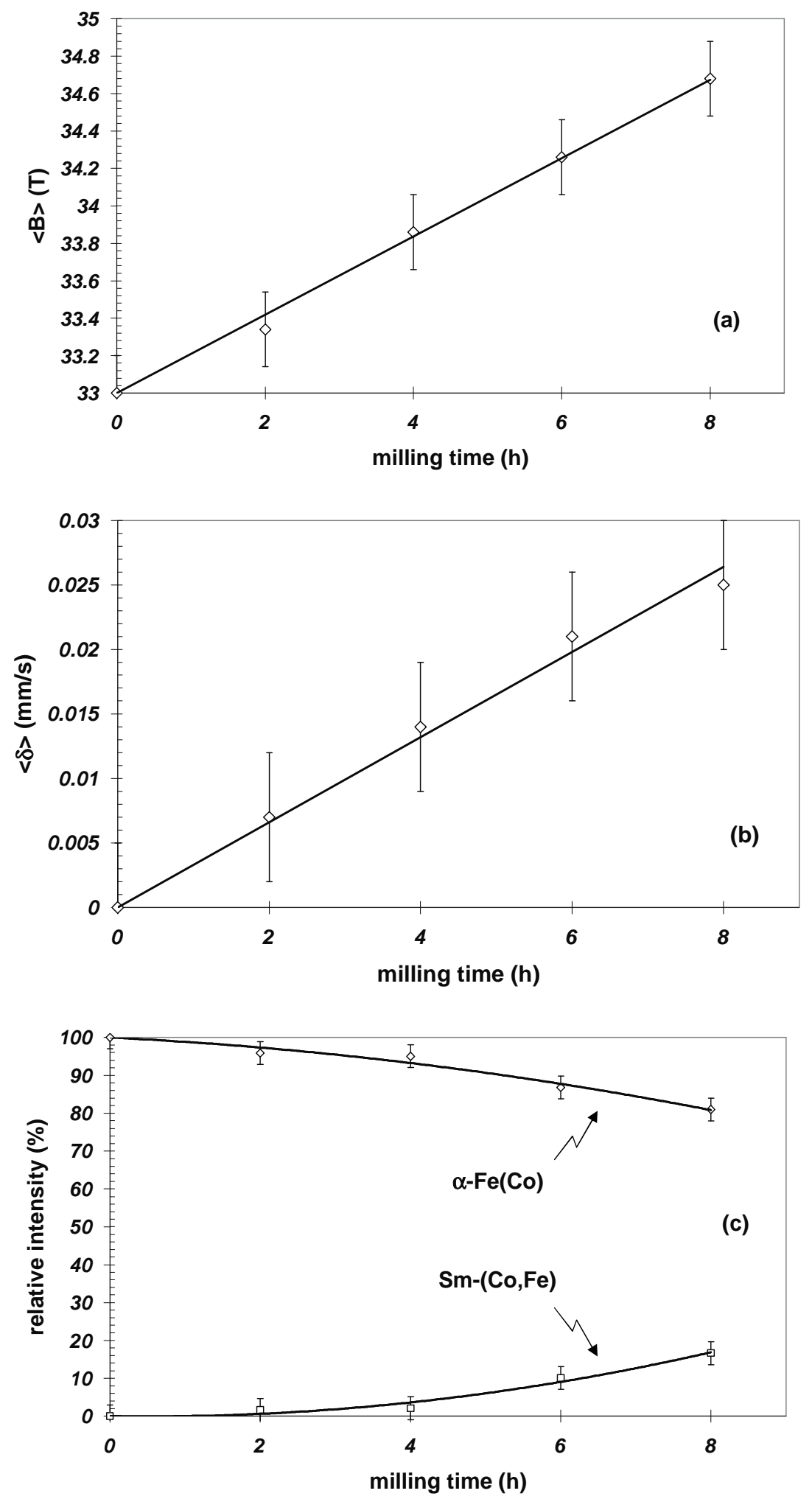

Figure 4. Evolution with the milling time of (a) the mean hyperfine field of the $\alpha-\mathrm{Fe}(\mathrm{Co})$ contribution, (b) the mean isomer shift of the $\alpha-\mathrm{Fe}(\mathrm{Co})$ contribution, and (c) the relative intentities of the $\alpha-\mathrm{Fe}(\mathrm{Co})$ and $\mathrm{Sm}(\mathrm{Co}, \mathrm{Fe})_{5}$ contributions. The lines are guides for the eye. 
The presence of $\mathrm{Co}$ in $\mathrm{Fe}$ and that of $\mathrm{Fe}$ in Sm-Co-rich regions is confirmed by LAWATAP analysis of the powder milled for $8 \mathrm{~h}$. A slice taken from the 3D reconstruction is shown in figure 5 and presents the spatial distribution of $\mathrm{Sm}, \mathrm{Co}$ and $\mathrm{Fe}$ atoms. The figure evidences the nanostructure of the sample and reveals that the distribution of $\mathrm{Sm}$ is not uniform. Sm atoms are only detected in Sm-Corich regions. The regions where $\mathrm{Sm}$ atoms are not detected correspond to the Fe-rich regions, which are initially occupied by the $\alpha$-Fe phase. Co atoms are detected in both the Sm-rich and the Fe-rich regions, with a concentration that is higher in the Sm-rich regions. Finally, $\mathrm{Fe}$ atoms are detected in all regions, i.e. they are also present in the Sm-rich regions. These results clearly show that $\mathrm{Co} / \mathrm{Fe}$ interdiffusion occurred during milling. A more detailed LAWATAP analysis will be published elsewhere [40].

These results clearly show that high energy ball milling of $\mathrm{SmCo}_{5}$ and $\alpha$-Fe leads to a partial mixing down to the atomic scale, leading to the diffusion of Fe atoms in Sm-Co-rich regions and to the diffusion of $\mathrm{Co}$ atoms in $\mathrm{Fe}$-rich regions. The $\mathrm{Co} / \mathrm{Fe}$ interdiffusion increases with the milling time.
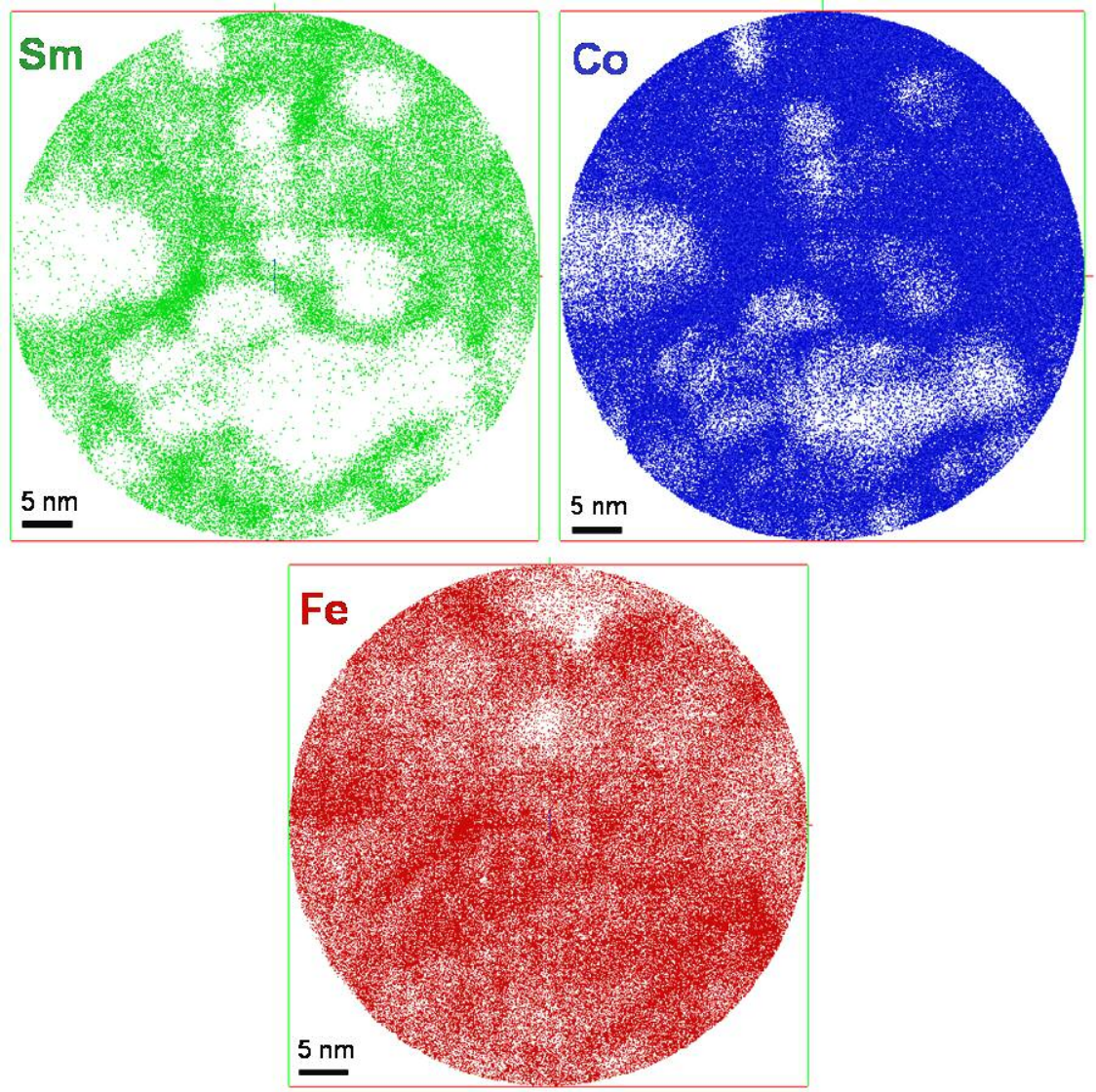

Figure 5. 2D projections of elemental mappings of $\mathrm{Sm}$, Co and Fe atoms in an analysed volume of the powder milled for $8 \mathrm{~h}$, obtained by LAWATAP. 


\subsection{Annealed powders}

The influence of the annealing time on the structure of the powders was investigated on samples initially milled for different times, upon annealing at $450^{\circ} \mathrm{C}$. For example, the Mössbauer spectra of the powder milled for $6 \mathrm{~h}$ and annealed for times up to $10 \mathrm{~h}$ is shown in figure 6 . As compared with the spectrum of the as-milled powder, the spectra of the annealed powders reveal an increase of the relative intensity of the $\mathrm{Sm}(\mathrm{Co}, \mathrm{Fe})_{5}$ contribution with the annealing time. Moreover, the mean hyperfine field $\left\langle\mathrm{B}_{\mathrm{Fe}}\right\rangle$ of the $\alpha$ - $\mathrm{Fe}(\mathrm{Co})$ contribution changes with the annealing time.

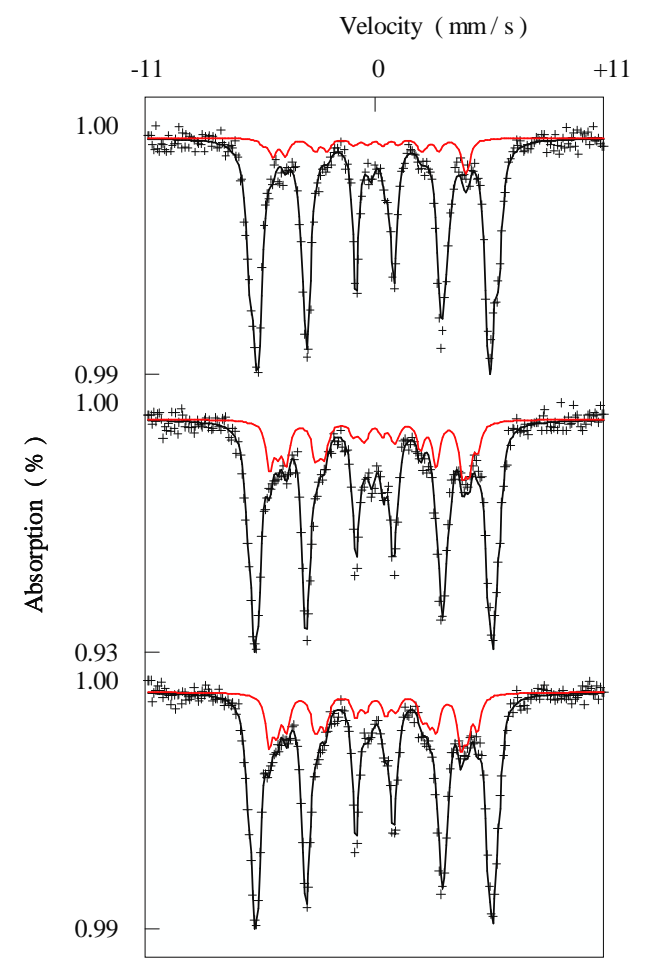

as-milled

annealed for $1.5 \mathrm{~h}$

annealed for $10 \mathrm{~h}$

Figure 6. Room temperature Mössbauer spectra of the $\mathrm{SmCo}_{5} / \mathrm{Fe}$ powder as-milled for $6 \mathrm{~h}$ and annealed at $450^{\circ} \mathrm{C}$ for the indicated times.

The contribution of the $\mathrm{Sm}(\mathrm{Co}, \mathrm{Fe})_{5}$ phase is displayed.

The same observations are made for the other samples. The evolution of the $\mathrm{Sm}(\mathrm{Co}, \mathrm{Fe})_{5}$ relative intensity and that of the $\alpha-\mathrm{Fe}(\mathrm{Co})$ mean hyperfine field are gathered in figures $7 \mathrm{a}$ and $7 \mathrm{~b}$, respectively. For all the samples, an important increase of the $\mathrm{Sm}(\mathrm{Co}, \mathrm{Fe})_{5}$ relative intensity occurs for short time annealing, followed by a plateau. This suggests that annealing promotes an increase of the Fe content in the Sm-Co-rich regions, up to a maximum value. The evolution of the mean hyperfine field of the $\alpha-\mathrm{Fe}(\mathrm{Co})$ contribution shows a similar behaviour, except for the sample milled for $8 \mathrm{~h}$, for which the annealing leads to a decrease of $\left\langle\mathrm{B}_{\mathrm{Fe}}\right\rangle$ before reaching the plateau. This does not mean that the Co content in Fe-rich regions decreases, if one considers that, according to [38], in $\mathrm{Fe}_{1-x} \mathrm{Co}_{\mathrm{x}}$ alloys with $\mathrm{x}>0.30$, the mean hyperfine field decreases as $\mathrm{x}$ increases. Accordingly, this suggests that for milling times lower than $6 \mathrm{~h}$, the Co content in the $\alpha-\mathrm{Fe}(\mathrm{Co})$ regions is lower than about 25 at.\% in the asmilled samples and increases with the annealing time, while for $8 \mathrm{~h}$ milling, the Co content in the $\alpha$ $\mathrm{Fe}(\mathrm{Co})$ regions is higher than about 25 at.\% in the as-milled samples and increases with the annealing time as well. 

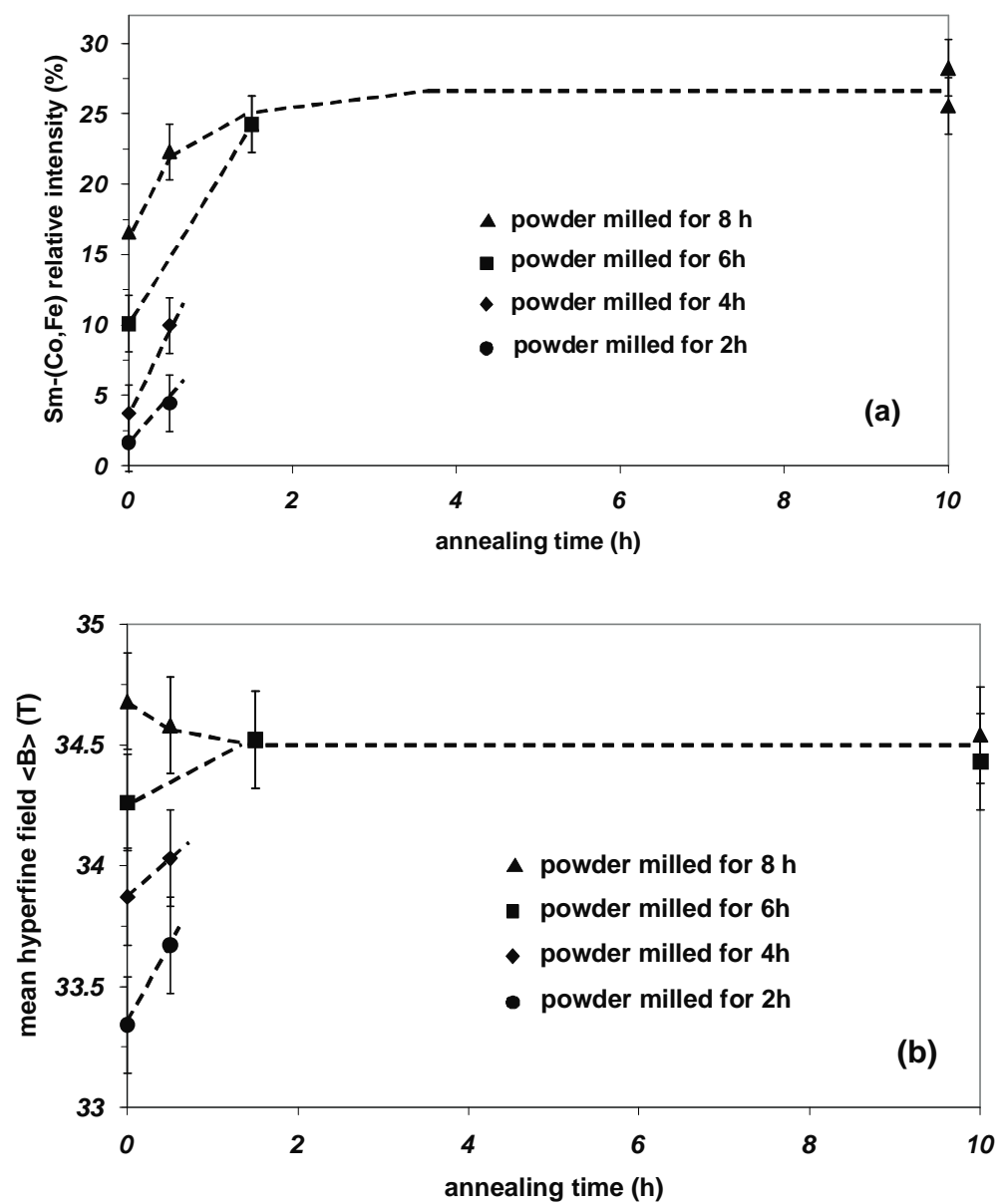

Figure 7. Evolution with the annealing time at $450^{\circ} \mathrm{C}$ of (a) the relative intensity of the $\mathrm{Sm}(\mathrm{Co}, \mathrm{Fe})_{5}$ contribution, and (b) the mean hyperfine field of the $\alpha-\mathrm{Fe}(\mathrm{Co})$ contribution.

The lines are guides for the eye.

The influence of the annealing temperature on the phases involved is investigated for the powders milled for $8 \mathrm{~h}$. The Mössbauer spectra of the powder before and after annealing for $0.5 \mathrm{~h}$ at temperatures up to $650^{\circ} \mathrm{C}$ are shown in figure 8 . As the temperature increases, the relative intensity of the $\mathrm{Sm}(\mathrm{Co}, \mathrm{Fe})_{5}$ contribution increases noticeably to reach about $60 \%$ at $650{ }^{\circ} \mathrm{C}$. This shows that the $\mathrm{Fe}$ content in the Sm-Co-rich phase increases with the annealing temperature. This is accompanied by a decrease of the mean hyperfine field $\left\langle\mathrm{B}_{\mathrm{Fe}}\right\rangle$ of the $\alpha-\mathrm{Fe}(\mathrm{Co})$ contribution, related to a concomitant increase of the Co content in the $\alpha-\mathrm{Fe}(\mathrm{Co})$ regions, and characteristic of a Co content higher than about 25 at.\% as explained above [38]. These results show that annealing up to $650^{\circ} \mathrm{C}$ leads to an important increase of the $\mathrm{Co} / \mathrm{Fe}$ interdiffusion. The relative intensity of the $\mathrm{Sm}(\mathrm{Co}, \mathrm{Fe})_{5}$ contribution after annealing at $650^{\circ} \mathrm{C}$ being $61 \%$ indicates that more than $60 \%$ of the $\mathrm{Fe}$ atoms are present in the Sm-Co-rich regions. 


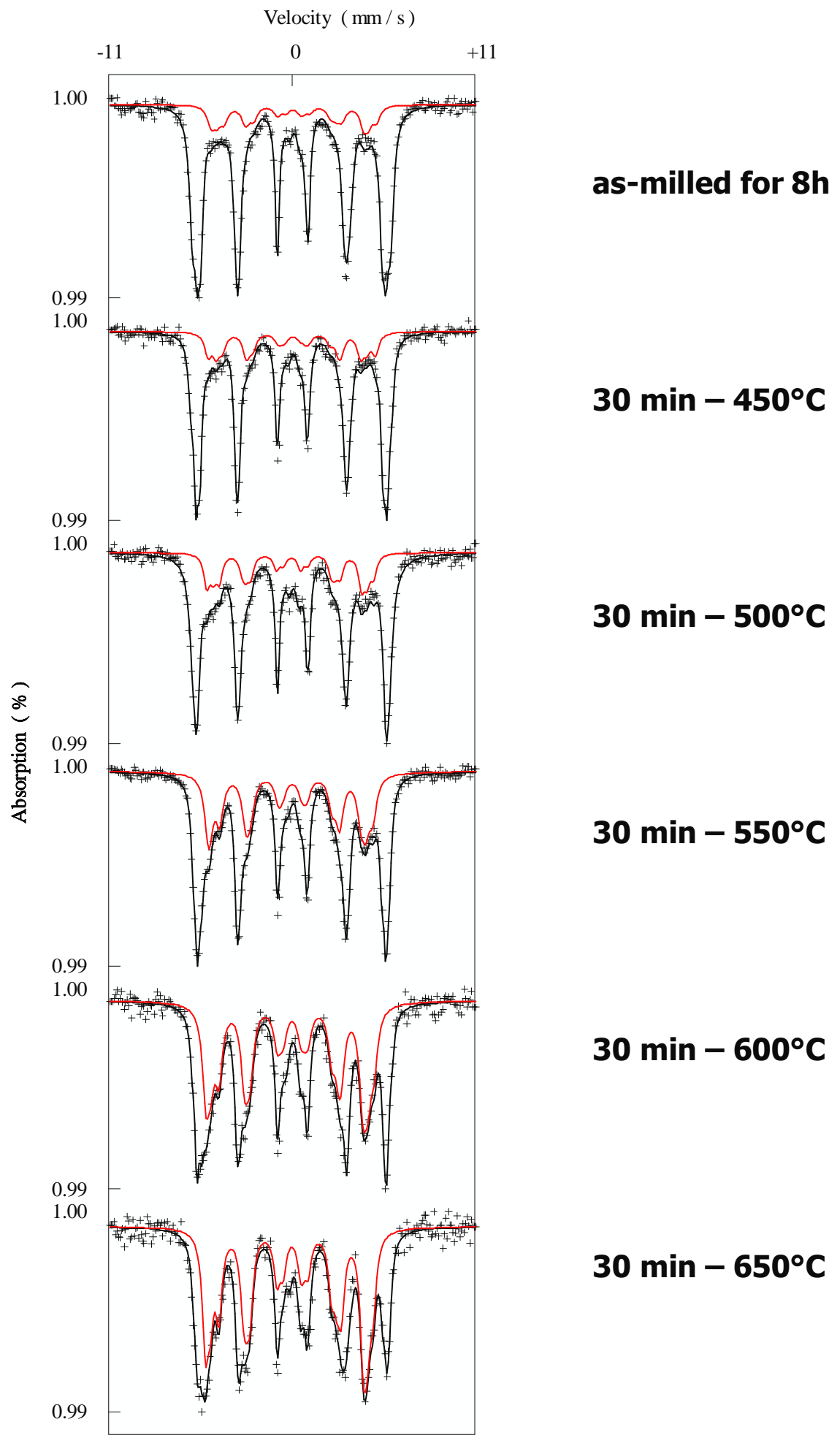

Figure 8. Room temperature Mössbauer spectra of the powder as-milled for $8 \mathrm{~h}$ and annealed for 30 minutes at the indicated temperatures.

The contribution of the $\mathrm{Sm}(\mathrm{Co}, \mathrm{Fe})_{5}$ phase is displayed. 
Thus, the tendency observed for long time annealing at $450^{\circ} \mathrm{C}$ is also observed for short time annealing at higher temperatures. Diffusion of Fe atoms in the Sm-Co-rich regions and diffusion of Co atoms in the $\alpha$-Fe regions occur simultaneously leading to the fact that both the $\mathrm{Fe}$ content in $\mathrm{Sm}(\mathrm{Co}, \mathrm{Fe})_{5}$ and the Co content in $\alpha-\mathrm{Fe}(\mathrm{Co})$ drastically increase with the annealing temperature. Such a structural modification of the phases involved is fully consistent with the evolution of the magnetic properties previously described in this type of alloys [11-14].

\subsection{Co/Fe interdiffusion and magnetic properties}

It is well known that the mean hyperfine field $\left\langle\mathrm{B}_{\mathrm{Fe}}\right\rangle$ of the $\alpha-\mathrm{Fe}(\mathrm{Co})$ contribution is related to the $\mathrm{Fe}$ content in the $\alpha-\mathrm{Fe}(\mathrm{Co})$ phase [38]. As the intensity of the $\mathrm{Sm}(\mathrm{Co}, \mathrm{Fe})_{5}$ contribution, denoted as $\%_{\mathrm{SmCoFe}}$, is proportional to the $\mathrm{Fe}$ content in the $\mathrm{Sm}(\mathrm{Co}, \mathrm{Fe})_{5}$ phase, the $\mathrm{Co} / \mathrm{Fe}$ interdifussion process during both milling and annealing can be represented by plotting the evolution of $\left\langle\mathrm{B}_{\mathrm{Fe}}\right\rangle$ as a function of $\%_{\mathrm{SmCoFe}}($ figure 9$)$. The experimental points reveal a behaviour that is in full agreement with the known evolution of the hyperfine field of $\mathrm{Fe}_{1-\mathrm{x}} \mathrm{Co}_{\mathrm{x}}$ alloys with $\mathrm{x}$, as shown by the insert to figure 9 . According to the nominal volume fractions of the $\mathrm{SmCo}_{5}$ and $\alpha$-Fe phases and neglecting the slight difference in density of these phases, the parameter $\%_{\mathrm{SmCoFe}}$ corresponds exactly to the Co content in the $\alpha-\mathrm{Fe}(\mathrm{Co})$ phase. This is confirmed by tomographic atom probe analysis as well. For example, in the powder annealed at $550^{\circ} \mathrm{C}$ for $0.5 \mathrm{~h}$ the measured Co content of the $\alpha-\mathrm{Fe}(\mathrm{Co})$ phase $(40 \pm 8$ at. \%) is fully consistent with the Mössbauer relative intensity of the $\mathrm{Sm}(\mathrm{Co}, \mathrm{Fe})_{5}$ contribution (39\%) [40]. Consequently, the evolution of $\left\langle\mathrm{B}_{\mathrm{Fe}}\right\rangle$ with $\%_{\mathrm{SmCoFe}}$ reflects the evolution of $\left\langle\mathrm{B}_{\mathrm{Fe}}\right\rangle$ with the Co content in $\mathrm{Fe}_{1-\mathrm{x}} \mathrm{Co}_{\mathrm{x}}$ alloys.

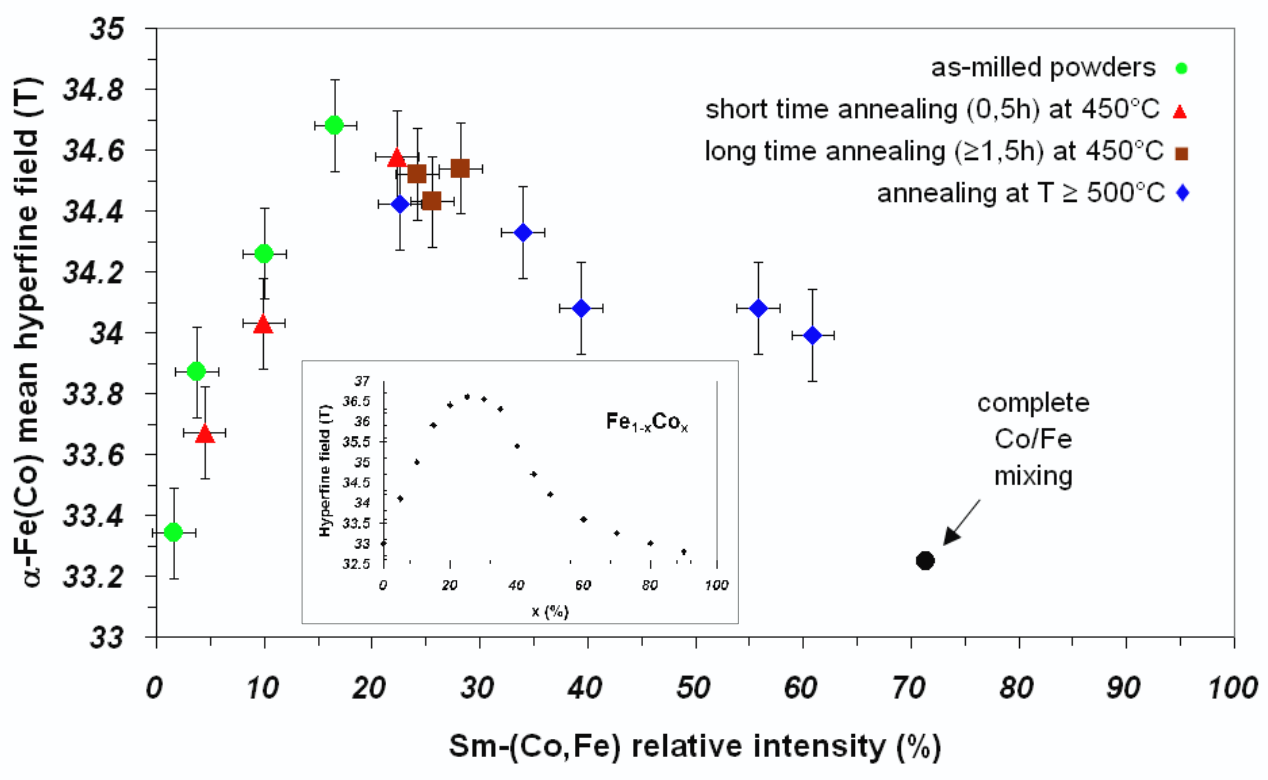

Figure 9. Mean hyperfine field of the $\alpha-\mathrm{Fe}(\mathrm{Co})$ contribution as a function of the relative intensity of the $\mathrm{Sm}(\mathrm{Co}, \mathrm{Fe})_{5}$ contribution, for all the samples investigated.

Insert: hyperfine field of $\mathrm{Fe}_{1-\mathrm{x}} \mathrm{Co}_{\mathrm{x}}$ alloys as a function of the Co content $\mathrm{x}$ in the alloy [38]. 
Comparing the $\left\langle\mathrm{B}_{\mathrm{Fe}}\right\rangle=\mathrm{f}\left(\%_{\mathrm{SmCoFe}}\right)$ curve (figure 9) with the $\left\langle\mathrm{B}_{\mathrm{Fe}}\right\rangle=\mathrm{f}(\mathrm{x})$ curve (figure 9 , insert), one can notice that the values of $\left\langle\mathrm{B}_{\mathrm{Fe}}\right\rangle$ are lower than those expected for $\mathrm{Fe}_{1-\mathrm{x}} \mathrm{Co}_{\mathrm{x}}$. Such a difference could be related to the small size of the $\alpha-\mathrm{Fe}(\mathrm{Co})$ particles and to the presence of defects.

Grouping all results, the various mechanisms involved in $\mathrm{Fe}$ vs $\mathrm{Co}$ interdiffusion can be summarized as follows: the increase of $\left\langle\mathrm{B}_{\mathrm{Fe}}\right\rangle$ with $\%_{\mathrm{SmCoFe}}$ for low values of $\%_{\mathrm{SmCoFe}}$ corresponds to the diffusion of $\mathrm{Fe}$ atoms in the $\mathrm{Sm}$-Co-rich regions. In this regime, the fact that $\left\langle\mathrm{B}_{\mathrm{Fe}}\right\rangle$ increases with the milling time shows that the diffusion process is mechanically activated.

Then, $\left\langle\mathrm{B}_{\mathrm{Fe}}\right\rangle$ reaches a plateau for $\%_{\mathrm{SmCoFe}}$ values of about 20 to $30 \%$, corresponding to a Co content in the $\alpha-\mathrm{Fe}(\mathrm{Co})$ phase of 20-30 at.\%. This is obtained for the powders milled for 6 and $8 \mathrm{~h}$ and annealed up to $10 \mathrm{~h}$ at $450^{\circ} \mathrm{C}$, which are characterised by further $\mathrm{Co} / \mathrm{Fe}$ interdiffusion.

The decrease of $\left\langle\mathrm{B}_{\mathrm{Fe}}\right\rangle$ observed for values of $\%_{\mathrm{SmCoFe}}$ higher than $30 \%$ corresponds to a further increase of the Co content in the $\alpha-\mathrm{Fe}(\mathrm{Co})$ phase. This is obtained for the powders milled for $8 \mathrm{~h}$ and annealed at temperatures between 550 and $650^{\circ} \mathrm{C}$. For complete $\mathrm{Co} / \mathrm{Fe}$ mixing, not observed experimentally here, the relative proportions of transition metals in each phase would correspond to their relative proportions in the initial mixture, that is 71 at.\% Co and 29 at.\% Fe. Thus, $\%_{\text {smCoFe }}$ would be equal to $71 \%$ and, according to [38], $\left\langle\mathrm{B}_{\mathrm{Fe}}\right\rangle=33.2 \mathrm{~T}$. The corresponding point reported in figure 9 is roughly aligned with the experimental points. It remains to be demonstrated whether increasing further the annealing temperature or the annealing time would lead to complete $\mathrm{Co} / \mathrm{Fe}$ intermixing.

Previous investigations of the magnetic properties of as-milled and annealed $\mathrm{SmCo}_{5} / \mathrm{Fe}$ powders revealed that the best magnetic properties are obtained for powders milled for $8 \mathrm{~h}$ and annealed at 550$600^{\circ} \mathrm{C}$ [11]. This corresponds to a relative intensity of the $\mathrm{Sm}(\mathrm{Co}, \mathrm{Fe})_{5}$ contribution, and thus to a Co content in the $\alpha-\mathrm{Fe}(\mathrm{Co})$ phase, comprised between 39 and $55 \%$. Annealing at such temperatures improves the exchange interactions [11]. Considering the present investigation, such an improvement has to be related to the presence of both $\mathrm{Co}$ and $\mathrm{Fe}$ in all the magnetic phases. Strong $\mathrm{Co} / \mathrm{Fe}$ interdiffusion may lead to better structural coupling between the $\mathrm{Sm}-(\mathrm{Co}, \mathrm{Fe})$ and $\alpha-\mathrm{Fe}(\mathrm{Co})$ phases, thus reinforcing the exchange interactions between the magnetically hard and soft phases. Such a positive effect of the $\mathrm{Co} / \mathrm{Fe}$ intermixing on the exchange coupling has been reported in the case of $\mathrm{SmCo}_{5} / \mathrm{Fe}$ exchange spring multilayer films $[41,42]$.

The evolution of the remanence in the present system is in rather good agreement with the evolution of the Co content in the $\alpha-\mathrm{Fe}(\mathrm{Co})$ phase. The highest remanence is obtained for the powder milled for $8 \mathrm{~h}$ and annealed for $1.5 \mathrm{~h}$ at $500^{\circ} \mathrm{C}$, which corresponds to a Co content of about 34 at.\%, close to the maximum value of the magnetization of $\mathrm{Fe}_{1-x} \mathrm{Co}_{\mathrm{x}}$ alloys [43]. Annealing the powder for shorter times at the same temperature or at lower temperatures leads to lower remanence, as expected for Co contents below 28 at.\%, and thus to a smaller value of the magnetization of $\mathrm{Fe}_{1-x} \mathrm{Co}_{x}$ phase. Annealing the powder at higher temperatures induces a remanence decrease, in relation with a decrease of the magnetization of the $\mathrm{Fe}_{1-\mathrm{x}} \mathrm{Co}_{\mathrm{x}}$ phase, its Co content being larger than $39 \%$.

The positive influence of an annealing treatment on the coercivity has to be related to structural modifications (grain size refinement and increase of the crystallinity), but it can be partly due as well to $\mathrm{Co} / \mathrm{Fe}$ interdiffusion, through reinforcement of the intergranular exchange interactions. However, annealing at too high temperatures probably leads to an increase of the grain size, thus permitting soft phase magnetisation reversal independently of hard phase reversal. This explains the appearance of a shoulder on the demagnetization curves as shown in ref. [11].

\section{Conclusion}

Milling a mixture of $\mathrm{SmCo}_{5}$ and $\alpha$-Fe magnetic phases leads to $\mathrm{Co} / \mathrm{Fe}$ intermixing: Co atoms diffuse in the $\mathrm{SmCo}_{5}$ phase and $\mathrm{Fe}$ atoms diffuse in the $\alpha$-Fe phase. This interdiffusion process is mechanically activated. Annealing the powders at temperatures up to $650^{\circ} \mathrm{C}$ leads to the formation of $\alpha-\mathrm{Fe}(\mathrm{Co})$ and $\mathrm{Sm}(\mathrm{Co}, \mathrm{Fe})_{5}$ phases. Increasing the annealing temperature leads to the increase in both the Co content in the $\alpha-\mathrm{Fe}(\mathrm{Co})$ phase and the $\mathrm{Fe}$ content in the $\mathrm{Sm}(\mathrm{Co}, \mathrm{Fe})_{5}$ phase. These results help in interpreting previous magnetic measurements on this system. In particular, the strong $\mathrm{Co} / \mathrm{Fe}$ interdiffusion evidenced in the present study may reinforce the exchange interactions between the magnetically hard $\mathrm{Sm}(\mathrm{Co}, \mathrm{Fe})_{5}$ and soft $\alpha-\mathrm{Fe}(\mathrm{Co})$ phases. 


\section{References}

[1] O. Gutfleisch, A. Bollero, A. Handstein, D. Hinz, A. Kirchner, A. Yan, K.H. Muller, L. Schultz, J. Magn. Magn. Mat. 242-245 (2002) 1277

[2] R. Hasegawa, J. Magn. Magn. Mat. 304 (2006) 187

[3] G.C. Hadjipanayis, J. Magn. Magn. Mat. 200 (1999) 373

[4] Y.Yoshizawa, S.Oguma, K.Yamauchi, J. Appl. Phys. 64 (1988) 6044

[5] G. Herzer, M. Vazquez, M. Knobel, A. Zhukov, R. Reininger, H.A. Davies, R. Grossinger, J.L. Sanchez, J. Magn. Magn. Mat. 294 (2005) 152

[6] E. E. Fullerton, J. S. Jiang, S. D. Bader, J. Magn. Magn. Mat. 200 (1999) 392

[7] E. E. Fullerton, J. S. Jiang, M. Grimsditch, C. H. Sowers, S. D. Bader, Phys. Rev. B. 58 (1998) 12193

[8] R. Skomski, J. Appl. Phys. 76 (1994) 7059

[9] R. Skomski, J. Phys. Cond. Mat. 15 (2003) R841

[10] R. Skomski, J. M. D. Coey, Permanent Magnetism, Institute of Physics Publishing, Bristol 1999.

[11] V. Pop, O. Isnard, I. Chicinas, D. Givord, J.M. Le Breton, J. Opto. Adv. Mat. 8 (2006) 494

[12] V. Pop, O. Isnard, I. Chicinas, D. Givord, J. Magn. Magn. Mat. 310 (2007) 2489

[13] V. Pop, O. Isnard, D. Givord, J.M. Le Breton, I. Chicinas, J. Opto. Adv. Mat. 10 (2008) 1872

[14] V. Pop, E. Dorolti, C. Vaju, E. Gautron, O. Isnard, J.M. Le Breton, I. Chicinas, Romanian J. Phys. 55 (2010) to appear

[15] L. Schultz, K. Schnitzke, J. Wecker, M. Katter, C. Kuhrt, J. Appl. Phys. 70 (1991) 6339

[16] K. O’Donnell, J. M. D. Coey, J. Appl. Phys. 81 (1997) 6311

[17] L. Wei, W. Qun, X. K. Sun, Z. Xin-guo, Z. Tong, Z. Zhi-dong, Y. C. Chuang, J. Magn. Magn. Mat. 131 (1994) 413

[18] J. X. Zhang, L. Bessais, C. Djega-Mariadassou, E. Leroy, A. Percheron-Guegan, Y. Champion, Appl. Phys. Lett. 80 (2002) 1960

[19] D. L. Leslie-Pelecky, R. L. Schalek, Phys. Rev. B. 59 (1999) 457

[20] D. Geng, Z. Zhang, B. Cui, Z. Guo, W. Liu, X. Zhao, T. Zhao, J. Liu, J. All. Com. 291 (1999) 276

[21] C. You, X. K. Sun, W. Liu, B. Cui, X. Zhao, Z. Zhang, J. Phys D: Appl. Phys. 33 (2000) 926

[22] W. Liu, Z. D. Zhang, J. P. Liu, X. K. Sun, D. J. Sellmyer, X. G. Shao, J. Magn. Magn. Mat. 22 (2000) 278

[23] R. Grössinger, Reiko Sato, J. Magn. Magn. Mat. 294 (2005) 91

[24] M.A. Al-Khafaji, W.M. Rainforth, M.R.J. Gibbs, H.A. Davies, J.E.L. Bishop, J. Magn. Magn. Mat. 188 (1998) 109

[25] P Saravanan, R Gopalan, N V Rama Rao, M Manivel Raja, V Chandrasekaran, J. Phys D: Appl. Phys. 40 (2007) 5021

[26] N V Rama Rao, P Saravanan, R Gopalan, M Manivel Raja, D V Sreedhara Rao, D Sivaprahasam, R Ranganathan, V Chandrasekaran, J. Phys D: Appl. Phys. 41 (2008) 065001

[27] P. Saravanan, M. Manivel Raja, R. Gopalan, N.V. Rama Rao, K. Suresh, D.V. Sridhara Rao, V. Chandrasekaran, Intermetallics 16 (2008) 636

[28] J. Teillet, F. Varret (1983) unpublished MOSFIT program

[29] R. Lardé, E. Cadel, F. Cuvilly, J. Bran, M. Jean, J.M. Le Breton, to be published

[30] B. Gault, F. Vurpillot, A. Vella, M. Gilbert, A. Menand, D. Blavette, B. Deconihout, Rev. Sci. Instr.77 (2006) 043705

[31] P. Bas, A. Bostel, B. Deconihout, D. Blavette, Appl. Surf. Sci. 87-88 (1995) 298

[32] D. Blavette, A. Bostel, J. M. Sarrau, B. Deconihout and A. Menand, Nature 363 (1993) 432

[33] D. Blavette, B. Deconihout, A. Bostel, J. M. Sarrau, M . Bouet, A. Menand, Rev. Sci. Instr. 64 (10) (1993) 2911

[34] J. Desportes, D. Givord, J. Schweizer, F. Tasset, IEEE Trans. Magn. 12 (1976) 1000

[35] J. Schweizer, F. Tasset, J. Phys. F: Metal Physics 10 (1980) 2799

[36] E. Burzo, A. Chelkovski, H.R. Kirchmayr, in: Landolt-Bornstein (ed.) Magnetic properties of metals, vol. 19d2, Springer, Berlin (1990) 
[37] M. Forker, A. Julius, M. Schulte, D. Best, Phys. Rev. B. 57 (1998) 11565

[38] C.E. Johnson, M.S. Ridout, T.E. Cranshaw, Proceedings of the Physical Society 81 (1963) 1079

[39] H. Moumeni, S. Alleg, J.M. Grenèche, J. All. Com. 386 (2005) 12

[40] R. Lardé et al. to be published

[41] J.S. Jiang, J.E. Pearson, Z.Y. Liu, B. Kabius, S. Trasobares, D.J. Miller, S.D. Bader, Appl. Phys. Lett. 85 (2004) 5293

[42] J. Zhang, Y.K. Takahashi, R. Gopalan, K. Hono, Appl. Phys. Lett. 86 (2005) 122509

[43] Magnetism and Metallurgy" Volume 2, A. Berkowitz and E. Kneller editors, Academic Press New York and London (1969) 